\title{
Research on English Moving Teaching Strategies Based on Wechat
}

\author{
Platform \\ Huahong Rao ${ }^{1}$ \\ ${ }^{1}$ Tongren University, Tongren, Guizhou, 554300 \\ 346591653@163.com
}

KEYWORDS: English Moving Teaching, Strategies, Wechat Platform

\begin{abstract}
With the development of mobile network technology, exchange of information and the way acquired undergone great change, at present, the use of smart phones using micro-channel users rapidly increased, as a micro-channel network chat tool exists, is a practical mobile learning English good platform. Survey of College Students through the use of micro letter, to propose and implement the use of micro-channel for English learning method helps to play a practical mobile learning English the role of micro-channel.
\end{abstract}

\section{Introduction}

We live in the information age, the speed of information continues to accelerate access to information methods and means expanding, mobile learning this concept is presented in the smart phone, communication tools to the evolving background, it makes learning is not time and place restrictions, greatly increasing the flexibility of learning, based on practical English mobile learning micro letter also makes learning English people loved to go through the form of penetration into people's daily lives.

Mobile learning is a way of obtaining new learning education information, educational resources and educational services use wireless mobile communications network technology and wireless mobile communication device.

\section{The Problems of Traditional IT Application in English Teaching}

While modern educational technology is the commanding heights of foreign language teaching reform in the education sector has reached a consensus, but there is a problem of information integration technology and foreign language teaching in universities in the specific practice: first, limited school funding, lack of adequate hardware and educational software and many devices faster product updates, product updates requires a lot of maintenance costs. Second, many existing educational media equipment, complex media software operation, did not play a role. "Training in educational technology capability requires a lot of costs, but also cannot be achieved in the short term. Foreign teachers lack skills with the appropriate technology, the impact of foreign language teachers the positive use of the media, which restricts the improvement of teaching methods, resulting in failure of educational technology and foreign language learning and language teaching and integrate. Furthermore, students through existing educational media devices, media software for information are often subject to time and space restrictions 


\section{The Feasibility of Mobile Learning}

With the continuous development of smart phones and the popularity of wireless network technology, mobile learning in college English Teaching already has a preliminary basis.

Currently, students use the phone into the mobile terminal using the Internet has become a habit. According to the China Internet Network Information Center statistics, as of June 2014, the total number of Internet users in China has reached 632 million mobile phone use rate of 83.4 percent, reaching 527 million, of which the student is still the largest group of Internet users in China, accounting for $25.1 \%$. When Internet users per week for up to 25.9 hours, the Internet penetration rate in this population is already at a high level, the smart-phone replace the function of the phone has been basically completed.

Mature with the development of wireless technology, especially web4.0 era required mobile learning network environment, a variety of wireless network coverage, students can use a mobile device easily Connect to a wireless network at high speed, rapid access education information, educational resources.

\section{The Wechat Technology}

Tencent micro letter on January 21, 2011 launch of an instant messaging service to provide intelligent terminal free application is a support cross-communications operators, cross-operating system platform. Compared with the SMS, micro-channel has its own advantages, with the support of flow under or in the area of wireless network coverage, micro-channel platform can not only deliver a text message, you can also transfer pictures, video, voice, etc., and can achieve Tencent news updates reminders, email reminders and other services, micro-channel users can also concerned about some of his own account of public interest to obtain information resources. Practical English teaching focus is to develop students' English skills and self-learning ability application, focusing on development of students, the use of micro-channel client, can make students autonomous learning, compared with the traditional English teaching mode, mobile learning more convenient and efficient. Micro-channel is simple, convenient, inexpensive, and efficient mobility applications software, widely used in the student population.

\section{Mobile Learning}

Mobile learning is referring to the help of mobile computing devices, the learning process can be performed at a different time and place. Mobile computing technology and Internet technology is the technical foundation of the emergence and development of mobile learning, mobile phones, tablet PCs and other mobile learning media. Compared with the traditional way of education, mobile learning has the following features: a: mobile learning has changed the study of time and place, so that learning is no longer confined to the timing of teachers and curriculum. Two: mobile learning help to increase the autonomy of student learning, make learning truly the students themselves as the main body, so that students can learn English under the leadership of interested arrange their own learning time and learning place, will be able to receive good results. Three: mobile learning enables interaction between learners greatly improved student learning, you can always ask the teacher to ask questions, help students to solve problems in a timely manner, helping to increase communication and interaction between teachers and students. 


\section{The Role of Wechat in Practical English Learning}

Micro-channel has taped function, use this feature, teachers and students can be 30 seconds of video conversation, content of the dialogue are required to use English, long-term exercise can exercise the students' speaking skills. Practical knowledge of English students will have learned English through dialogues and exercises effective use of the actual exchange go, therefore, learning practical English oral training is the most important, but also the focus of teaching content. Teachers in each class after class to set a figure for dialogue session, require students to work in pairs to communicate in English, the contents of the students to the dialogue recorded and uploaded to the circle of friends, teachers select relatively good circle of friends Play video conversations, and students have guidance on dialogue, so that educational teaching methods flexible, targeted, it is novel, can greatly enhance students' interest in learning English.

The use of micro-channel group, teachers can publish relevant teaching tasks and jobs, students can communicate or consult with teachers and other students through micro-channel group, make English learning and discussion can be carried out anywhere. Micro-channel groups can increase communication and exchange between teachers and students, to facilitate closer relations between teachers and students, to create a good learning environment, helping students to solve problems in a timely manner, and significantly enhance students' English learning.

- Discussion groups can be established by means of micro-letter, all students in the discussion group to discuss today's after-school tasks, which is a new model of group discussion, group discussion and cooperation so that learning is no longer confined to the classroom and the school, and It can be carried out anytime, anywhere. Discussion groups can effectively avoid the student time is not uniform, and no way to meet after school to discuss the issue together, but also can record the contents of the discussion in the form of audio and text down, easy to sum up in the future.

Push learning materials through micro-channel public platform. Teachers can create micro-channel platform through a public accounts, students focus on the use of mobile terminals or subscribe to this account can receive push teachers to learn about this, and can interact with this account. Micro-channel also has an automatic reply feature, you can learn the content in the form of graphic materials stored on the server, students need only send specific entries can read the content. For example:

\section{Effective Way to Promote Mobile Learning English}

Human resources to do construction work. Micro-channel platform with automatic reply, achieve a variety of real-time communications and other functions, but also has many applications and is a good platform for mobile learning can make up the traditional teaching model of education deficiencies. In order to make full use of network resources, to play micro-channel platform to promote mobile learning practical English, need to constantly improve human resources building, construction of a high-quality, high-level teachers. English teachers must have a solid foundation of professional, strong English skills in listening, speaking, reading and writing can give students good guidance and recommendations to help students improve their ability to use English and practical English teaching quality requirements for teacher is strict.

In the continuous development of information technology today, the security of network information systems gradually attracted people's attention. Micro-channel platform has a very important role in practical English mobile learning, but there are invisible threats, the use of 
micro-channel platform for mobile learning can indeed improve learning ability of students, but if only the micro-channel platform as a portable chat tool It will move to the loss of the significance of learning, so students should use appropriate micro-channel platform, and constantly improve their self-control, fully functional micro-channel platform to improve their English proficiency. .

\section{Conclusion}

The development of communication technology and network technology are progressively changing our way of life learning, mobile learning will be a major development trend of learning. The use of micro-channel platform for mobile learning has been accepted by most people, learning practical English-based mobile micro-channel platform to help make up for the shortcomings of traditional teaching methods, convenient communication platform to facilitate exchanges and communication between teachers and students, facilitate access good teaching effect. I believe in the future, based on micro-channel mobile learning will gradually improve and get promotion and popularization in everyday teaching, making lifelong learning really become a reality.

\section{REFERENCES}

[1] Yan Yilan learning theory CET miniature mobile learning research --- empirical research under the guidance of micro-channel public platform [J] based on science and technology horizon, 2013 (25): 97.

[2] Wang Ping micro-channel mobile learning support functions and design principles [J]. Journal of Distance Education, 2013,10 (43): 523-578. 